\title{
THE SECRET, A HIDDEN-FOUND PROCESS
}

\author{
Gabriela Romaneț $t^{13}$
}

Abstract: Following the secret's customs, encountering it in the myriad manifestations of psychic life and relational domino effect, the current work separates the secret from the act of secretiveness and from trauma, with which the former often confused. The fact that it is intrinsically linked to truth, as it is hidden information waiting to be found, defines the secret as a process involved in working with information-about-self and the self: it is a joy to be hidden and a disaster not to be discovered. This hidden-found process that accompanies us our whole life is transformed according to the biological and psychological stages one must go through. Thus, the secret is interpreted differently, passing through successive stages of development. From the archaic game of "hide-and-seek", through the primitive scene of "peeping through the keyhole" and discovering the secret of one's own genitals, continuing with the type of secret offered by a relationship of friendship in latency, reaching the desecretisation and de-sacralisation of adolescence, the secret is an "act of secrecy" that requires an interior architecture as well as borders between the internal and external universe. Otherwise, the "act of secrecy" fails and turns into secretiveness, a failure of the hidden - found process, because either nothing can be hidden (as in paranoid mechanisms) or everything must be hidden (as in trauma mechanisms).

Keywords: the incommunicado self, hidden-found process, act of secrecy, failure of secrecy, secretiveness, anti-knowledge 


\section{Introduction}

From the very first session, face to face with a person we are just meeting, we quite explicitly tell the analysand that we are committed to keeping the secret of his or her anonymity. Thus, the plot and the intrigue of the secret emerge from the very first minutes of the session. The rule is asymmetrical, meaning that this person is free to speak as much as he/she wants to whomever he/she wants. However, after we have established this setting separate from the exterior, the secret is present even in the relationship that is about to form. The secret continues to be present long after this moment, because the analysand will avoid shame and the exposure of vulnerabilities, or will manage rejection, or will keep the traces of identity, allowing the preservation of the self.

As the term is not indexed in psychoanalytic vocabulary and not included in the specific dictionaries, yet encountered in countless manifestations of life, affecting psychic life and relationships, I wonder: Why do we open the relationship with the ethics of secrecy? Why is it so natural to do so and not otherwise? Is the secret just a defence? Why does it carry such negative connotations, even though we rely on it to lay the foundation for a trusting relationship? Why is it associated with lying, betrayal and schizo-paranoid mechanisms? Or with splitting into a "secret life" as a parallel one, with a "secret self" as dissociated self? What bothered us humans so much that we rejected the existence of a plot based on the secret, utopically dreaming of a world without secrets?

And yet, the right to privacy and anonymity is part of the International Human Rights, as a foundation for the respect of human nature. We are in debt to this "uncanny" term (I'm alluding to Freud's 1919 article, "The Uncanny") to question it and, indeed, to elaborate it. So, what does the secret have as specific functioning?

First of all, negative aspects are difficult in exploring the secret. We're referring to negative aspects such as the dysfunctional secrets related to entangled connections and attacks on our sense of reality, lies, betrayals, dissociations and secret lives, secrets that disturb the continuity of existence. In short, we are referring to secretiveness. Secretiveness as a way of life creates distance and opposes intimacy and closeness, in fact representing failures in the "act of secrecy" - here using the term of Pierre Janet (1927), who refers to the secret as an act of thinking, differentiation and decision. 118 
We think, therefore we symbolize, differentiate between what can be said and what cannot be said and then decide whether to say it or not. It is a whole information-based mechanism that one can choose to use or not. This definition is specific to the secret and involves the development of a superego, and, should we want to be more precise, it is about the post-oedipal super-ego.

Erich Fromm, in an unpublished chapter from 1975, "To have or to be?", says:

"In many persons there are two such plots: A conscious, "official" one, as it were, which is the cover story for the secret plot that dominates our behaviour. (...) Oedipus' secret plot is to kill his father and marry his mother; his conscious and intended life plot is to avoid this crime under all circumstances. Yet the secret plot is stronger; against his intention and without awareness of what he is doing, he lives according to the secret plot." (Bacciagaluppi, M., Biancoli, R., 1993, p. 441)

Thus, the unconscious, playing the part of the "great film director", works with the draft of the "secret" script and creates one visible narrative and another underground one, hidden from view and knowledge. Is one true and the other false? In working with the unconscious, we cannot operate with binary thinking of the true-or-false type because the truth is intrinsically linked to the secret. They rely on one another, and the secret is also based on the defence of the unconscious. We hide and we uncover, this is the "plot".

In imagining the customs of the secret, observing it at work, it appears as a "plot" in the creation of symptoms (secretising the desire and motives of suffering, yet also preserving and making them active), in creating dreams and interpreting them, in slips of the tongue, in any manifestation of the unconscious and in the attempt to discover the significance of unconscious actions. We find it in the relationship between the ego, the one who has to manage the secrets, like a secretary, and the super-ego, the one who authorizes whether or not information can be used, like an administrator. Unauthorized information can be hidden in the body when there is no psychic space for it to be "narrated". Wherever we look in psychic life, the script of the secret is a process: we hide and we hide ourselves, to be found or not be found. We know what we are hiding or we do not know what we are hiding. Two scenarios unfold - repression intervenes, when the ego waits for a more opportune time for the information to return, or splitting intervenes, when the ego keeps away from itself aspects of its own history that have not been subjectivised, 
metabolized, waiting for symbolization and the encounter of a person who would allow it to redo that part of history. Nevertheless, it is certain that we will hide and wait to be found.

Imagining a world without secrets would not be psychic life. There would be no curiosity or confidentiality, no sincerity or trust and no possibility to think otherwise. To mobilize secrecy and truth, we need emotional strength, curiosity, honesty, tolerance of mystery - we need a moment of creation.

Looking for what is specific to the secret, we find the secret in the unconscious as part of the truth: it sets defensive mechanisms for the defence of the existence and it bothers us when it is not utilised for growth and when it fails in attacks on linking. It has two phases: hidden information about a reality waiting to be found. I define the secret within the hidden - found process and will attempt, following its development, to identify the conditions pertaining to its existence and failure, of its existence as a hidden - found process or the failure of this process, i.e. when nothing can be hidden (as in paranoid mechanisms) or when everything needs to be hidden (as in trauma mechanisms).

\section{The incommunicado self or the right to not be communicated}

It seems important to establish from the outset the self has the right to not be communicated. Winnicott (1963) speaks of this self, having this right, calling it the incommunicado self-the private self, the self in secrecy, isolated without being insular, having not only the right not to be communicated, but the demand, requirement and necessity not to be influenced by external reality, expecting only to be contained by it. It needs space in which to hide, waiting to be progressively discovered and respected, not unveiled and shamed, not stolen, plundered and violated, not accused of lying.

Psychoanalytic technique also takes into account the core of the self, the incommunicado self, in following the patient without overtaking him or her. We do not advise the analysand, but instead offer him support to discover his own path, we respect his own rate of progress, we respect his defences and we interpret what is close to the conscious. Winnicott (1963) places the resistance and hatred of society towards psychoanalysis within the fear of intrusion on the core of the self. Psychoanalysis has the rule of "telling all" at its centre, thus something which may be associated with the violation of the self. There are things to be communicated and others not to be communicated, 120 
and psychoanalysis has to manage the non-sexual, spiritual and moral issues, the penetration and violation of the self, respecting the patient's need for not communicating and the human trait of being withdrawn, private, in secret.

"It is a joy to be hidden but disaster not to be found" is the paradox formulated by Winnicott (1963, p. 186) in regards to the incommunicado self.

\section{It is a pleasure to play hide-and-seek}

From the very first meeting, the analysand hides and waits to be found. Or he doesn't hide. He doesn't want to hide, even refuses to play, being terribly afraid that he won't be discovered. Or the patient will just stay hidden because he has many secrets, which he will reveal over time, little by little, as he will come to trust the other and as he gains the certainty that the liberty to come closer or move away will remain. The patient will conquer internal space to transform personal representations of the self through this game of engaging and disengaging with the analyst.

Perhaps the patient will want to sit face-to-face, not on the sofa, where he would feel regressed, reduced to the position of one depending on maternal care, passive, abandoned to the anxieties of annihilation or paranoid anxieties and experiences of losing internal / external boundaries, the me / you delimitations. The patient will lose the meaning of existence without integrated representations about the other and, implicitly, integrated representations of the self. The narcissistic-identity disorders cannot handle the sofa, where a game of hide-and-seek would begin between different representations of self and non-self and between different personifications of the other; where a game of force and upheavals that allow a psychic revolution would begin.

As the relationship develops, the patient, like any human being, has to manage two aspects: on one hand, he needs attachment, therefore requiring a connection with the invested object, and, on the other hand, he needs identification, therefore separation from the invested object, in order to live his self, both with an intersubjective meaning and as a subject with an own body and mind and a separate identity. Whether these currents run parallel to each other or clash when one comes in too early or too late, too much or too little, one's identity demands to be defined from the perspective of both.

If, for a time, the "mother - womb" bond will contain the mother-baby dyad and symbiosis, later this connection will be experienced along with a conflict stemming from dependency on the "mother - breast" and the resulting 
anger as she is the one who decides the moments of presence and absence. She decides when to remove herself or disappear from the baby's field of vision, controlling the moments of encounter and separation, gratification and frustration. A revolution is developing and, because the child can now use his motor skills, he will use muscle control to compensate for the narcissistic wound that addiction implies. He will begin to "remove" himself from her gaze, to refuse his mother, to hide, repeating the pattern of the mother's coming and going from his room. He'll start playing hide-and-seek. The baby could wait behind a door, under the table, in a corner, behind the curtain, for the mother to worry and begin looking for him, enjoying that she reacts to his disappearance, perceiving the affective states that his disappearance produced. If the mother does not react and will not immediately go looking for him, he will feel scared and lost.

And here's how, in a relationship in which the foundations of attachment and separate identities are established from the start, in which both "we" and "I" live, the game of hide-and-seek is both the experience of influence on the object and the experience of asserting one's own will, one's desire and one's own conflict. The double action that one must take in order to gain a foundation in subjectivity, to be attached and separated at the same time, a regressive tendency to restore the fusion with the lost object and a progressive tendency to consolidate the differences, leads to sometimes focusing on the relationship and attachment, and other times on identity and self.

"I hide so you may find me and share the joy of individuation with me". This is the secret of the archaic period, a game of detachment, hiding and seeking, with an emphasis on seeking, because it means reunion.

\section{The super-ego and acquiring the concept of secret}

Continuing along the subject of attachment and connection with the invested object, relationships with significant others will constitute the complex world of internalized object relationships and will ultimately determine the structure of the ego, the super-ego and the Id. The super-ego will be created according to the model provided by the relationship with the parents. It will become the replica of the outside world inside the child. The hidden - found process in the hide-and-seek game, along with the establishment of the superego, has an internal replica of the external scene. Initially, certain thoughts and feelings are hidden from parents and, subsequently, the ego conceals the 122 
same thoughts, feelings and other psychic phenomena from the super-ego and even from some parts of the ego.

The second important deciding factor that gives the secret a specific functioning is the super-ego, the one that authorizes whether or not certain information can be used by the ego in its attempt to resolve conflicts.

The moment when a person reveals a secret to us is a moment that we interpret differently, depending on the attachments psychic development has been anchored to, i.e. depending on the emotional and biological age of the person. The secret in the archaic is different from the secret in secondary narcissism, and different from the post-oedipal secret, just as it is interpreted differently in adolescence.

In secondary narcissism, when the super-ego is the inner replica of the mother or father, their voices, eyes and ears, the child experiments perception and deepens knowledge on the difference. The thinking of the child from this period and, implicitly, the secret, are means of exploration through the perceptions and the body animated by development. I will elaborate in the following paragraphs.

In the anal stage, the secret is perceived as a possession that must be retained or evacuated, the secret is a secretion. The moment a patient confesses or discloses a secret or entrusts it is equivalent to the urgency of the discharge of an excretory organ, and the reaction to secrets is similar to that of secretions in general. What is evacuated from the body represents a ghostly bearer of unintelligible and distressing experiences. And the secret, too, is based on the body, on what the body produces, on that unintelligible thing to be evacuated or to be held in. It is in the anal organization of the drive that we find the "toxic secret" - the unspoken one, the one that must remain hidden, the one that should not be symbolized, tolerated or endured, on which the trauma mechanism is based.

In the phallic stage, there is a tendency to use the secret in an exhibitionist way in games of hide-and-seek, "look, I have it, I'm proud of it", waiting to perceive confirmation or support in the other's eyes. The phallic child depends on the parents' gaze, expecting to be "found" from this look, feeling proud when viewed and admired, or fearing rejection and shame when viewed and threatened with castration.

In what concerns boys, Selma Fraiberg (1956), in a psychoanalytic study of the child, talks about the myth of discovering secret riches often found in fairy tales. She states that the accidental discovery of a secret leading 
to treasure in such tales is equivalent to the moment in which the child, accidentally touching his genital organs, discovers the secret of the genital organs and understands the hidden power of the 'evil sorcerer' father. This is an indication of the nature of the child's masturbating fantasies. There is the mystery of childhood, of the existence of a "place where the treasure (access to the woman) is hidden and the child's belief that, if he had magical objects, such as the pirates' map, the clues leading to such a "place", he could outsmart his competitor, his rival, and thus win the treasure for himself. $\mathrm{He}$ would be a hero, vanquishing an evil opponent and marrying the princess, or elevating his mother through wealth and prestige after defeating his foe. The danger and fascination of the theme of castration are condensed into fantasies of beheading, incarceration and threats from the "magic lamp". However, the emotional jolt of this period that characterises the phallic child and the potency of boys consists of the consoling conviction that the mother needs treasures, more and more money, which the boy procures for her.

Girls, when speaking of the difference between the sexes, discover their vagina, which is hidden from view, hidden from the test of castration anxiety. The girls are unable to verify its presence or absence. Due to the physiological constitution, the vagina is found through instinctual impulses, attempts at masturbation or pain caused by minor injuries of the hymen. Karen Horney (1933), in "The Denial of the Vagina: a Contribution to the Problem of the Genital Anxieties Specific to Women", speaks of the early importance of "vagina discovery" for the development of femininity. If undiscovered or subjected to assiduous repression, it will remain a "denied vagina", a fantasy that the vagina does not exist, and it will be replaced with penis envy. By discovered we mean that, once the vaginal sensations and the corresponding impulses are felt, the girl must at first have a vivid feeling of this specific character to her own sexual role and the attributes specific to her sex: vulnerability, motherhood, mystery. The danger of finding is condensed into penetration anxiety, rape, burglary or injury phantasms.

Most secrets originate as derivatives of oedipal conflicts, when the child creates different relational strategies focusing on the parental couple. In his attempt to cope with oedipal desires, he can identify the secret in adult sexuality and internalize the secret as a substitute formation, i.e. a relational intrigue with the "secret" as a theme. The child senses the existence of a sexuality that escapes his observation. The hidden part becomes enigmatic for him, contradicting, confusing, revolting, but also exciting. The child 124 
feels excluded from the relationship that unites the two adults and develops relational strategies, imaginary and symbolic, to attack the parental couple. All fantasies will be guided by the process of hiding his subjective stake and hiding himself, to avoid punishment for attempting to fulfil forbidden sexual desires.

The oedipal child must make sense of the subjective experience. He must invest it in order to integrate what he experiences into the fabric of the ego the experiences of pleasure and displeasure and the conflicts that pleasure and displeasure generate. The senses, which he constructs, coagulate in "infantile sexuality theories", in his attempt to explain the enigmas of sexuality (his sexuality and his parents' sexuality) and the enigmas of his origin and presence in the world. Thus, the fantasy of the primitive scene, of castration and seduction, shows what the child knows from actual manifestations and what he imagines about what he does not know, while also intuiting the origin of his own person, sex and desire. Curiosity is not necessarily a desire to learn the truth, but rather a need to know what other people know, according to George Devereux (1952). To enlighten the child too early and, conversely, to inhibit the development of curiosity, may produce intellectual inhibitions in the child's attempt to construct a theory of the world and life based on secrets and intrigues, on lies and falsehood, in accordance with the understanding specific to his biological age and in harmony with his psychological age.

The fear of punishment and the fear of losing the parents' affection are two types of anxiety that mobilize defences, thus allowing the prohibited drive activity to be continued in secret, hidden and undiscovered. "The child pretends to feel 'bad' in situations where he actually feels 'good'. And from this lie morality was born”, says O. Fenichel (1945, p. 123). He learns to hide the inner world from the eyes and ears of parents, to lie and pretend. It is the indicator of the existence of a border between what is within him and an act of decision concerning what can be said and what cannot be said. The surface is reorganized into a post-oedipal form, becoming autonomous, i.e. no longer the voice, eyes and ears of parents.

When launched in the processes of autonomization that aim to conceal a part of his life from the eyes of adults, from their critical view, he gains the ability for abstraction, an important acquisition. 'I'm hiding and I don't want you to find me". This is where we are reminded of children going through puberty, ones who begin to shout at their parents "Leave me alone! Knock before coming in!" But it also brings to mind angry parents, parents who are 
almost grieving because of the limit that their children set, experiencing the feeling that they have lost their children and resorting to desperate gestures, full of reprisals and resentments, so as to not be further removed.

The flow of development continues, when it goes well and is not restrained by a parent who cannot survive and cannot reinvent himself, taking on the evolved form of a parent of an older child. The child crosses another threshold in the process of becoming autonomous and the process of separation will be carried out even in relation to the family, before leaving to conquer extra-familial spaces.

The process of thought is also reorganised, going from the exploratory mode through perception to thinking through representation. The child invests its own activity of symbolic representation, communication and progressive discovery of the world and its rules, classing them as very valuable. The latency period starts when the representation begins to be taken as a new drive purpose, being satisfied and comforted by the representation that satisfies drives and brings on relaxation. It will have to symbolize what it cannot accomplish in the drive life. The child symbolizes them to induce latency, and from this symbolization, he discovers that he has an inner life that is not visible, thus becoming aware that his own thoughts are not accessible to others.

Russell Mears (1988), following a study carried out with Orlay that focused on 40 children, notes that this moment occurs at the age of 5, when social existence is made aware. It is not a system we are born with, but one we obtain after we go through the successive stages of development that result in the constitution of the border between one's mind and the mind of others. The decision the child makes to say or not to say what is significant in his or her inner life depends on the awareness of one's own intimacy.

"This point in the child's development is signalled by the momentous discovery of secrecy at about the age of four... The acquisition of the concept of secrecy represents the birth of the self'. (R. Mears, 1988, p. 653)

The secret is no longer a part of the body animated by development. The secret is no longer "the disaster of not being found", instead becoming an "act of secrecy", a gift, a relationship offer, the initiation of a friendship or the creation of intimacy in a relationship, the object gaining value because it is chosen to be shown that hidden part of the self that seeks symbolization, the part yearning to be "born" (created, formed, experimented, represented) and to be found. Aware of social existence, with a boundary between inner and 126 
outer life, between private and public life, a person becomes able to operate with the "act of secrecy" and becomes aware of the right to be private without being isolated.

I recall a 9 years old girl, Ina, who I treated for 3 years. She was brought to therapy by her mother, despite her father generally not approving of the child's therapy. The mother did not know how to build a relationship with her daughter and the father did not believe that Ina had any reason not to be a happy child. Yet Ina described herself as being shy, the most attentive in class, priding herself with her compliance and absence of hostility, but this did not make her happy because she had no friends. The other children would make fun of her, and at home her sister was the family favourite. Her father was suffering from bipolar disorder, with a manic psychotic episode, with delusions of being followed and delusions of persecution, which induced a state of shock and trauma upon the entire family. At one point, for certain reasons. We had online therapy sessions through skype. In one session, because her father was "deliberately hearing" what we were talking about, she put her headphones in and obtained a "nightingale" (a wind instrument, a whistle shaped like a bird that works using water). Depending on the level of water in it and the amount of air blown, this whistle produces different sounds that imitates the chirping of birds. Our agreement was that she would use this chirping to speak to me, and I would reply and she'd hear me in her headphones. A deeper sound would mean confirmation, or whenever she let out a longer whistle it meant she wanted us to talk more about a certain subject, if there was an agitated whistle, she was angry and complaining about something. She would gently blow the whistle when 'singing' about confidence and distrust, she'd chirp about the guilt of not having any trust, conducting, with confidence in her own abilities, the orchestra of voices. Using a nightingale's trills, of varying intensities, we both entered a charmed, lyrical state of grace, of the incommunicado, building a connective bridge to her - as she also had to hide - wanting to be found for a relationship.

Before going further, along the developmental path, to adolescence, we will illustrate two failures of the "act of secrecy" as failures of the hidden found process: first in the paranoid version, where nothing can be hidden, and then in the trauma version, where everything must be hidden. 


\section{Nothing can be hidden: a failure of the "act of secrecy"}

One patient, Cris, says that Jesus could hear the obscene word in her mind, the one she says when things don't go her way, and God punished her with phallophobia. She goes into therapy reporting how she greatly fears that people can see the grime inside her. Her anxiety was intense as her job required her to be publicly exposed. The feeling of transparency was always with her. The boundary between inner life and outer life is blurred, leading to fear, and paranoid anxieties occupied all psychic sectors. For some time, being in therapy, she withdrew from any outside-the-ego activity. The therapeutic relationship became akin to persecution, with me being perceived as a sadistic and persecuting super-ego who does not allow her to drink alcohol, to be famous, the reason she lost her "chances". She was behaving as if I was the one not handing out job offers in interviews, and, when she participated in an interview, as if I was the one never hiring her. Blaming me, she would want to take control of my super-ego. To become active in telling her what to do, for example. I end up feeling helpless, angry, hateful and unwilling, with the constant impression that I am trapped in a captive, symbiotic relationship. Through tyranny, she tries with all her strength to destroy my internal landmarks, my view of the world, of life and my values, in order to establish herself in place of my super-ego to control me and, of course, to make me submit.

The intrusion on my inner space bears witness to the way she experienced closeness. Her fear, her enormous demands, her fury that I am not omnipotent, followed by the disappointment that I cannot help her, the invasion, feelings of insecurity and helplessness, the interdiction of having a self and self-esteem. Her growth was halted by an intrusive environment, a mother who wanted to know everything her child thought. A mother who lived in states of non-differentiation and non-separation, who relied on the fantasy of shared skin. The patient's mother was not interested in anything concerning her daughter, but was interested only in her own role: she was the one who gives, who takes, who hands out grades, awards, clothes, material prosperity, pills, physical and mental health.

Nothing can be hidden. Everything is in sight, accessible to anyone, without psychic skin, without a membrane separating the inner and outer life, exposed to all. The experience that accompanies the failure of hiding in the "act of secrecy" is "to sink into the ground out of shame", a form of primitive 128 
annihilation anguish. My patient's self, like the self of a paranoid person, is fundamentally experienced as being depraved and sinful. In a relationship, the fear that the other sees and discovers these sins and, as a result, will punish and reject her, makes her feel humiliation and shame that she is revealed in front of him. Unconsciously, she expected to be discovered, transforming this fear into constant and exhausting efforts to unmask the bad intention of the relationship partner, deliriously focusing on the alleged motives of the other, the one who would like to discover her, and not on what is happening internally. She constantly accuses me of wanting to find her.

In these cases of failure of the "act of secrecy", a question I have often asked myself is what does she want to hide so much, what does she fear is showing, regardless of defences, failing in defences? Piera Aulagnier (1975), talking about the paranoid potential of hatred in the parental couple, says that the paranoid acknowledges the need for parents to recognize themselves as the fruit of hatred, to realize the origin of existence as a result of eroticized hatred of parents, a form of perversion. Desire and hatred are inextricably linked, kept alive as long as they persist in a relationship with someone who she "hates", with something "to hate", continuously and automatically extrapolating tyranny and submission beyond intimate relationships, into the social sphere. Within the therapeutic setting Cris reiterates desire and hatred as an alternative form of relationship, an alternative to the close relationship she experiences with homosexual anxiety.

Thus, the hidden process for individuation - found in love and prepared for a relationship - is invaded by the absence of the dialectic between attachment and separation, between connection and individuation, the absence of borders between inside and outside, the denial of the vagina, the eroticization of hatred. I would speak of failure of the "act of secrecy", in which the fear of not being found is experienced with annihilation anxiety, which she defended herself against with an attempt to create a "false self" ideal, unchallenged, beloved, wanted, one that has nothing to hide, nothing to find, nothing to see, i.e. without psychic life, a zombie, as we both called the expected "false self".

\section{Everything must be hidden: taboo}

Another patient, Adryana, in her childhood was locked inside the house without being able to open the front door. Inside the house, some of the rooms 
were also locked, and in the few that were open and available to her the storage rooms, cabinets and phone were locked, forbidden to use. When her mother was at work, she left the bathroom, kitchen and bedroom unlocked (their bedroom, hers and her mother's, she didn't have her own bedroom). Until the divorce, the father was always away for work and came home one weekend a month, so her parents didn't need a matrimonial bedroom. The patient took the attack on her sense of reality in the state of captivity as a challenge to survive, to trick the mother's prohibitions, to escape impenetrable walls, to be creative and to have strength and power. She had learned to unlock doors and use the phone, even if she had a lock on the phone disc, and talk to strangers. She had learned how not to get bored in the house alone, imagining she had another family. She was not so easily defeated, she says, but at the age of 3 she had been raped by a teenage neighbour when her mother was not so drastically vigilant. Her childhood was marked by stomach pains, a burning sensation in the abdomen and diarrhoea. Up to the age of 10 , her body was the only one talking about what had happened. The information was hidden in the body. When a repeat incident occurred with a neighbour who had a key to her apartment door and tried to approach her sexually, Adryana remembered.

Working with her for 11 years, I discovered the forms of the secret and the "act of secrecy" failures in the trauma, the anti-knowledge and the secretiveness. The Bionic term - K (anti - K), anti - knowledge describes a process of undermining knowledge, which seeks to destroy and impede the process of knowledge, of forming relationships, of growth, life and existence. If we consider knowledge as a process that creates bonds between more people and connects the signs, the traces, the symptoms in a sense, then antiknowledge is a manifestation of the "attack on the connection", a hindrance and a prohibition of meaning. Anti-K, an inter-subjective process, will spread, like a relational domino effect, over all trans- and inter-generational links. Thus, a pattern of understanding, meaning and communication is constructed based on the taboo.

Secretiveness is a way of life, a way of functioning, involving the deconstruction of inter-subjective mechanisms, aimed at defending against the wounded narcissism of a family, produced by an insufficiently symbolized and elaborated trauma. The content that must be buried or repudiated is the one that causes shame, guilt, suffering, torment and trauma. It should not be spoken of, should not be symbolized, should not be tolerated or endured. It is something that must magically disappear, something that the mind cannot 130 
comprehend. There is no place for reality or for the elaboration represented by the principle of reality. The traumatic event destroyed the order of reality, and from this point on reality will be either bypassed or profoundly ugly.

One day, after 8 years of therapy, she tells me: "From now on, we'll communicate using the email address I first contacted you with. I no longer remember the password from my (current) address, I only remember the password from that email address, which is not very active". Yes, we had specific means of communication: a phone number (belonging to a SIM card she'd insert in the phone now and then, only when she wanted to talk to me or to her father) and an email address, or two, it seems. Her forgetting the password drew my attention. Not because forgetting one's password is a rarity, but I found it strange for her, who usually delivered such clear and precise instructions in working with information, to "forget" a password, one allowing access to a current email address she used daily for work. It was peculiar that this was lost in the "big" repression. The (parallel) email address was based on a name other than her own. As if she had an official identity out in sight, and another unofficial and hidden one. I would often find that, after a few good months, I'd wake up somewhere else and didn't know where. I was lost. I had the dream that I was going from one island to another, without a map or an overview. Finally, I felt my perspective broadening as a connection linking the insular information that I had on her emerged. This was the moment when I managed to connect the "islands", to map them out and build bridges.

Adryana "placed" the information in her body, in my mind (through projective identification), in the split parts of herself, in symptoms, in behaviours. She encrypted and encoded them in a way that made you get better and better at deciphering and decoding them, turning you into a CIA agent, a Sherlock Holmes, a great aficionado of unravelling secrets and taboos. In fact, it turned you into a great and impassioned hide-and-seek player. She'd attack some of the placed information, impeding their meaning, signification, and thus also preventing the inter-subjective, anti-K process, while signifying others. Some she'd bury while others she'd dig up, all at the same time.

\section{De-secretisation and de-sacralisation in adolescence}

Biological and sexual maturation produces a reshaping of the psychic, which will lead to a crisis in all sectors of psychic and relational life. The most important event of adolescence concerns the body. The adolescent must 
integrate sexual maturation and its effects on psychic organization. The new ability they must cope with is the potential to experience an orgasm, a specific sexual discharge, for which the teenager needs a novel drive solution that will produce a new way of experiencing pleasure, and not just sexual pleasure, but an entire psychic life governed by the principle of pleasure.

When he understands what was impossible to understand before, the teenager suffers a shock, a trauma. Now he understands what has been evading his comprehension, now he understands the language of passion, the impact of orgasmic experience in relation to the world. The secret of the enigma that was latent during childhood is revealed. Something that has been there for a long time is clarified and changes its previous meanings. Something that was hidden in adult sexuality and enigmatic, he now finds in himself, revealing the secret of the world. It is the prototypical experience of the hidden - found process in adolescence, of the secret, which will provide the fundamental meaning in "après-coup", i.e. retrospect understanding.

The pattern of revealing a secret hidden in appearances marks a change in the relationship with oneself and with the world. Nothing can be holy after discovering the secret of adult sexual pleasure. The orgasmic pleasure and drive will have to be introjected in the ego in a way allowing the ego to bind and integrate them subjectively. He will have to face the threat from within, the threat of the death of thought, the "symbolic killing", to gain the right to enjoy his self, to find himself, to take possession of himself and to reclaim himself back from his parents.

\section{Conclusions}

I will end with an illustration about "hot drink" mugs, the so-called magic mugs. Decorated with a partially visible image, once they are filled with hot liquid, the image on the mug is transformed, revealing a hidden side. This was brought to my attention by a lady who told me that she had trouble with such a mug, one she thought she'd damaged because she'd been washing it too much. The blue colour on it had disappeared and another drawing had appeared, but she was puzzled when, after a while, she saw that it was blue again. She quickly dismissed it as an illusion, a hallucination. Perhaps she simply had the impression it was no longer blue, allowing this experience to fade from his mind, without questioning or giving it thought, both fearful and joyous that she hadn't actually broken anything. The "secret" of the mug gave 132 
her an "uncanny" impression, the one Freud (1919) speaks of, via the return of the repressed. Something that had to stay hidden rises to the surface. It returns from the repressed and hits the consciousness with new information, something that had until then been unauthorized for use. The hot liquid acts as a revealing substance and brings out an image that was there, but that needed special conditions to become known. The image was always there, just under other conditions.

\section{REFERENCES}

ABRAM, J. (1996). The Language of Winnicott. Clunie Press, Perthshire.

AULAGNIER, P. (1975). Potențialitatea psihotizantă a urii și a violenței în cuplu [The psychotic potential of hate and violence in couples]. In Roussillion, R., Chabert, C., Ciccone, A., Ferrant, A., Georgieff, N. \& Roman, P. (editors) Manual de psihologie și psihopatologie clinică generală [Manual of general clinical psychology and psychopathology]. EFG, Bucharest, 2010, pp. 433-435.

BACCIAGALUPPI, M. \& BIANCOLI, R. (1993). Frommian Themes in a Case of Narcissistic Personality Disorder, Contemp Psychoanal, 29:441-452.

DEVEREUX, G. (1952). Intellectual Inhibitions and the Social Context, Bul Amer Psychoanal Assn, 8(3/4):300-359.

FENICHEL, O. (1945). Teoria psihanalitică a nevrozei [Psychoanalytic theory of neurosis]. Trei Publishing House, Bucharest, 2013.

FREIBERG, S. (1956). The Psychoanalytic Study of the Child. An Annual 9, 1954, Int J Psychoanal, 37:214.

FREUD, S. (1919). Straniul [The Uncanny]. In Opere [Works] (vol. 1). Trei Publishing House, Bucharest, 1999, pp. 253 - 283.

HORNEY, K. (1933). Negarea vaginului. O contribuţie la problema angoaselor genitale specifice femeilor [Denial of the vagina. A contribution 
to the problem of genital anxieties specific to women]. In Psihologia femeii [Female psychology], Trei Publishing House, Bucharest, 2012.

MEARES, R. (1988). The Secret, Lies and the Paranoid Process, Contemp Psychoanal, 24:650-666.

WINNICOTT, D.W. (1965 [1963]). Communicating and not communicating leading to a study of certain opposites. In: The Maturational Processes and the Facilitating Environment. Hogarth Press, London, pp. 179-192. 